\title{
An Integrated Approach for Characterization of Polyamide Reverse Osmosis Membrane Degradation due to Exposure to Free Chlorine
}

Sirikarn Surawanvijit, Anditya Rahardianto and Yoram Cohen*

\author{
Department of Chemical and Biomolecular Engineering \\ University of California, Los Angeles \\ 420 Westwood Plaza, Boelter Hall 5531 \\ Los Angeles, California 90095-1592
}

Submitted to Journal of Membrane Science: 24 June 2015

Revised Submission: October 31, 2015

$2^{\text {nd }}$ Revision: February 17, 2016

* Corresponding author: Tel: +1 310 825-8766; fax: +1 310 206-4107. E-mail address: profyc@gmail.com (Y. Cohen) 


\begin{abstract}
Reverse osmosis (RO) polyamide (PA) membrane integrity loss, performance degradation, and alteration of surface properties due to exposure to chlorine were evaluated experimentally via a fluorescent marker (uranine) based method, water permeability and salt flux measurements, and surface characterization via XPS, AFM and contact angle measurements. Membrane exposure to chlorine $(4-200 \mathrm{mg} / \mathrm{L} \mathrm{NaOCl}$ solutions) revealed that although membrane surface roughness increased with chlorine exposure intensity (ppm-hr), surface hydrophilicity increased as inferred by the decline (up to $5.2 \%-9.6 \%$ ) of the surface energy of hydration. Comparative analysis of marker transport for membranes that have undergone chlorine exposure of 125 - 2000 ppm-hr demonstrated that the membrane marker permeability coefficient (B) increased by up to a factor of $\sim 5$ relative to the intact membrane. While the severity of membrane integrity loss/performance degradation correlated to a reasonable degree with ppm-hr of chlorine exposure, the severity of membrane integrity loss, at the same chlorine ppm-hr, was greater for higher exposure concentration. Membrane integrity loss, over the same exposure levels, was quantified by an equivalent cylindrical breach that was in the range of about $14-40 \mu \mathrm{m}$, increasing in size with the intensity of chlorine exposure.
\end{abstract}

Keywords: chlorine exposure, polyamide, reverse osmosis, membrane integrity monitoring, membrane characterization 


\section{INTRODUCTION}

Thin film aromatic polyamide (PA) based membranes are widely used in reverse osmosis (RO) processes due to their high water permeability and salt rejection [1], which are paramount for high quality drinking water production to meet increasing water demands [2-7]. Chlorine type disinfectants are often dosed into the RO feed stream to prevent biological membrane fouling (biofouling) [3, 8, 9], as well as cleaning agents to enhance biofoulants removal from RO membrane surfaces [10]. However, chlorinated disinfectants (free chlorine, chlorine dioxide, and monochloramine), which are used in various RO brackish water and seawater desalination plants [11], can result in PA membrane oxidation [12-16]. Disinfectants that provide $\mathrm{HOCl}$ and $\mathrm{OCl}^{-}$ are aggressive oxidants that can adversely affect membrane performance [17]. When chlorine gas $\left(\mathrm{Cl}_{2}\right)$ or sodium hypochlorite $(\mathrm{NaOCl})$ are present in the $\mathrm{RO}$ feed water[18], they undergoe hydrolysis to form hypochlorous acid $(\mathrm{HOCl})$, which is further deprotonated to form hypochlorite ion $\left(\mathrm{OCl}^{-}\right)$. Membrane degradation can occur via orton rearrangement where rapid $\mathrm{N}$-chlorination leads to ring chlorination followed by an intramolecular rearrangement, as well as via chlorination of amidic nitrogen where chlorine attacks the lone electron pair of either $\mathrm{N}$ or $\mathrm{O}$ atom of the amidic group which leads to form $\mathrm{N}$-chloroamide [13]. As a result, conformational changes or cleavage of the membrane PA polymer can take place leading to PA membrane performance loss and thus the concern with potential passage of pathogens to the permeate stream in water reuse applications [19]. PA membrane manufacturers typically recommend that chlorine concentration in the RO feed should not exceed $0.1 \mathrm{mg} / \mathrm{L}[13,14,18,20]$, but concentrations as high as $4 \mathrm{mg} / \mathrm{L}$ can be reached in RO plant operations [20, 21].

It is generally accepted that exposure of a PA RO membrane to chlorinated disinfectants can have a measurable impact on the membrane physicochemical characteristics (i.e., chemical composition, surface wettability, and tensile strength) $[18,22-24]$ and performance (i.e., salt 
rejection and water permeability) $[12,14,15,17,24]$. However, there are widely different reported impacts. For example, previous studies $[12,14,15]$ reported a decrease in salt rejection and an increase in membrane permeate flux and permeability, while others reported increased in salt rejection and decreased membrane permeability (or permeate flux) [17, 24]. It was postulated that increased salt and water transport across the membrane was due, in part, to reduced crosslinking density of the polymer matrix, as suggested by a decline in tensile strength of the PA layer [23]. Increase in permeate flux was also attributed to increased membrane surface hydrophilicity $[18,22]$. In contrast, it has also been argued that decreased salt transport and water flux across the membranes was due to "tightening up" effects, caused by increased crosslinking of PA chains during oxidation, thereby reducing membrane permeability $[14,25$, 26]. It was also suggested that observed flux decline may have been due to decreased membrane surface wettability upon exposure to chlorine $[14,25]$. The contradiction in reported studies regarding the impact of membrane oxidation may be due, in part, to differences in experimental conditions, including differences in chlorine exposure period, concentration range, $\mathrm{pH}$, membrane type, and water quality. It is also important to note that the procedures of exposing PA membrane to chlorine, e.g., immersion versus RO cell operation (e.g., at specific cross flow velocity and transmembrane pressure), can result in different levels of surface oxidant concentrations even for the same feed concentration (i.e., due to concentration polarization in the latter approach [27]). Therefore, in order to clarify the impact of exposure to free chlorine on PA membrane performance, it is necessary to unambiguously evaluate the significance of chlorine exposure period and concentration under controlled experimental conditions.

The present study presents a multipronged approach to evaluating the influence of chlorine exposure conditions (i.e., concentration and exposure time) on the alteration of PA membrane performance, surface properties, and integrity loss. Membrane exposure to chlorine was carried 
out in a plate-and-frame RO (PFRO) system and the impact on membrane surface properties was quantified with respect to changes in surface chemistry, topography, and wettability. In addition, degradation of membrane performance due to exposure to chlorine was assessed with respect to permeate flux and salt rejection. The severity of membrane integrity loss was further quantified via a molecular marker approach in term of marker membrane permeability and reflection coefficient, in addition to an "equivalent breach size".

\section{EXPERIMENTAL}

\subsection{Materials and Reagents}

A flat-sheet polyamide ESPA2 RO membrane (Hydranautics, Oceanside, CA), which is commonly used for RO desalination of treated wastewater [28], was used in a bench-scale RO system. The membrane has an average permeability of $4.63 \mathrm{LMH} / \mathrm{bar}$, and an observed salt rejection of $99 \%$ (for 1,000 mg/L NaCl solution). Reagent-grade sodium hypochlorite ( $\mathrm{NaOCl})$ solution (5\% free chlorine, Fisher Scientific, Pittsburgh, PA) and ultra-pure deionized water from a Milli-Q water purification system (Millipore Corp., San Jose, CA) were used to prepare chlorine solution for the membrane degradation experiments. Reagent-grade sodium metabisulfite $\left(\mathrm{Na}_{2} \mathrm{~S}_{2} \mathrm{O}_{5}\right)$ (Fisher Scientific, Pittsburgh, PA) was used for removal of free chlorine residual from the RO system at a ratio of 3:1 (by mass) of $\mathrm{Na}_{2} \mathrm{~S}_{2} \mathrm{O}_{5}$ to free chlorine residual. For salt rejection test, sodium chloride $(\mathrm{NaCl})$ solution was prepared from ultra-pure deionized water and reagent-grade $\mathrm{NaCl}$ powder obtained from Fisher Scientific (Pittsburgh, $\mathrm{PA}$ ).

\subsection{Reverse Osmosis (RO) System}

A plate-and-frame RO (PFRO) system was utilized (Fig. 1) having cell channel dimensions of $2.81 \mathrm{~cm}$ (width) x $7.7 \mathrm{~cm}$ (length) x $0.25 \mathrm{~cm}$ (height) with an active membrane area of 21.6 
$\mathrm{cm}^{2}$. The RO feed (water or $\mathrm{NaOCl}$ chlorine solution) was fed to the membrane feed channel using a high pressure pump (Hydra-cell D/G-03, Wanner Engineering Inc., Minneapolis, MN) from a stirred and temperature-controlled 20-L feed reservoir. The desired flow rate and pressure were set by adjusting the pump variable frequency drive (VFD), bypass and backpressure valves. Feed and permeate flow rates were monitored using digital flow meters (Flowcal 5000, Tovatech, South Orange, NJ, and S-112, Georgetown, TX, respectively), and feed pressure was monitored with a digital gauge pressure (PGP-25B-300, Omega, Stamford, CT).

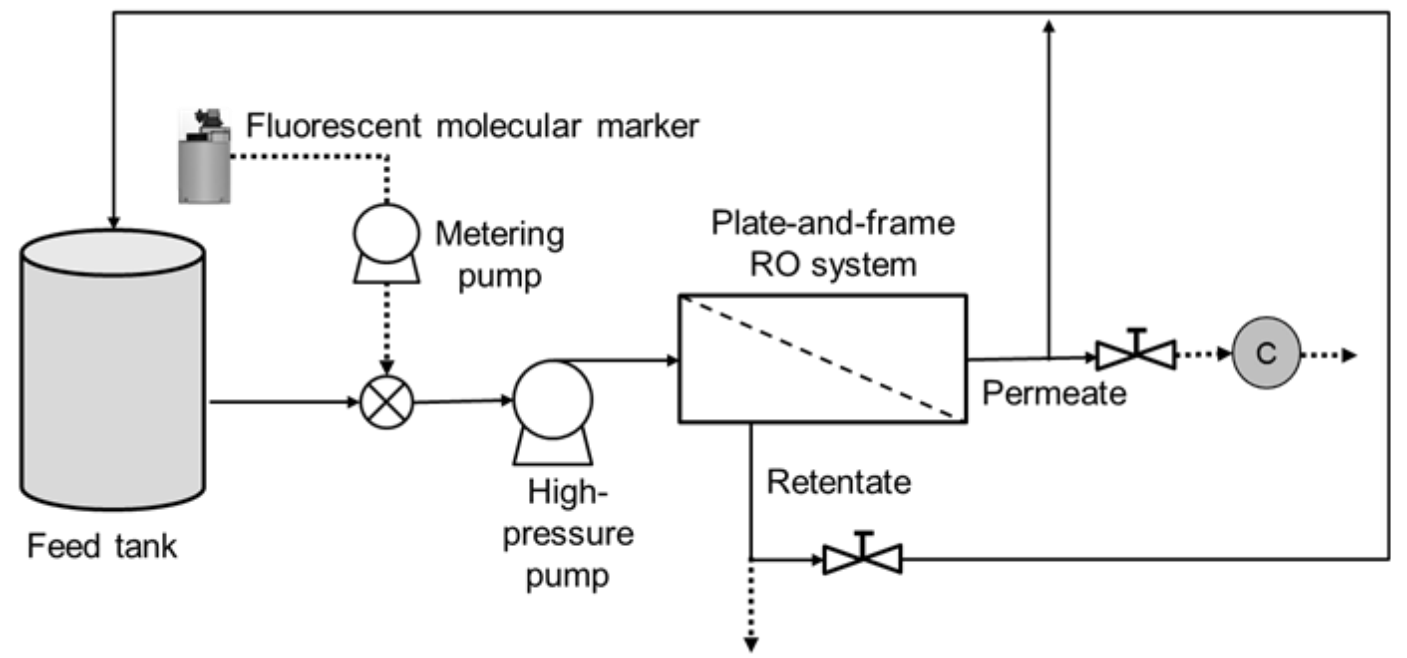

Figure 1. Schematic of the plate-and-frame RO system. The system was operated in a total-recycle mode (both permeate and retentate streams were recycled back to the feed tank) during membrane degradation experiments (i.e., exposure to chlorine), water permeability and salt rejection with salt solutions. The system was operated in a single-pass mode (both retentate and permeate stream are discharged, as represented by the dotted lines) during membrane characterization (post exposure to chlorine) using a fluorescent marker.

For the membrane degradation experiments and salt rejection tests, the PFRO system was operated in a total-recycle mode (retentate and permeate streams are recycled back to the feed reservoir). For the membrane integrity testing with the fluorescent marker, the PFRO system was operated in a single-pass mode (i.e., retentate and permeate streams were discharged). All RO 
experiments were conducted at transmembrane pressure range of 6.9-10.3 bar, permeate flux in the range of $9.3 \times 10^{-6}-1.3 \times 10^{-5} \mathrm{~m} / \mathrm{s}$, and $0.18 \mathrm{~m} / \mathrm{s}$ cross-flow velocity (Reynolds number of 490, based on channel height).

\subsection{Degradation of PA Membrane due to Chlorine Exposure}

The impact of membrane oxidation on $\mathrm{RO}$ membrane performance and integrity were evaluated in a PFRO system using a commercial ESPA2 membrane. ESPA2 membrane was cut into $3 \mathrm{~cm} \times 8 \mathrm{~cm}$ coupons, soaked in a DI water bath, and stored at $4^{\circ} \mathrm{C}$ in the dark for at least 24 hours prior to use. The membrane coupon, after being placed in the PFRO cell, was exposed to $\mathrm{NaOCl}$ solution $(50-200 \mathrm{mg} / \mathrm{L}$ feed concentration at $\mathrm{pH} \sim 7$ ) for a prescribed exposure period $\left(2.5-10\right.$ hours) at $22^{\circ} \mathrm{C}$ during $\mathrm{RO}$ operation in a total recycle mode at a transmembrane pressure of 6.9 bar (permeate flux of $9.3 \times 10^{-6} \mathrm{~m} / \mathrm{s}$ ) and cross-flow velocity of $0.18 \mathrm{~m} / \mathrm{s}$. At the above $\mathrm{pH}$, the molar ratio of $\mathrm{HOCl}$ to $\mathrm{OCl}^{-}$in the solution is 0.80 to $0.20[26,29]$. Also, it is noted that the concentration of chlorine at the membrane surface was higher than the feed concentration due to concentration polarization as quantified by Eq. 3 .

Following the membrane oxidation, the chlorine solution was discharged from the RO system which was then flushed with DI water in a single-pass mode at 10.3 bar for 15 minutes, followed by a total-recycle mode at 10.3 bar for 30 minutes, and subsequently single-pass mode operation at 10.3 bar for another 15 minutes. Any remaining chlorine residual in the PFRO system was removed by circulating $100 \mathrm{mg} / \mathrm{L}$ sodium metabisulfite $\left(\mathrm{Na}_{2} \mathrm{~S}_{2} \mathrm{O}_{5}\right)$ solution in the PFRO system at 6.9 bar for 30 minutes. The $\mathrm{Na}_{2} \mathrm{~S}_{2} \mathrm{O}_{5}$ solution was then flushed from the PFRO system with DI water until the chlorine retentate concentration was down to at least $0.1 \mathrm{mg} / \mathrm{L}$. Chlorine concentration in the RO retentate and permeate streams were measured by the DPD 
method [30] using a chlorine color disc test kit (CN-66 model, Hach, Loveland, CO), which is suitable for detecting chlorine concentration up to $\sim 3.4 \mathrm{ppm}$ at sensitivity of $\pm 0.1 \mathrm{ppm}$.

\subsection{Evaluation of Membrane Performance and Integrity}

Membrane performance before and after membrane exposure to free chlorine was assessed with respect to water permeability and salt rejection. Water permeability $\left(L_{p}\right)$ was determined via water flux $\left(J_{v}\right) v s$ transmembrane pressure $\left(\Delta P_{m}\right)$ measurements (i.e., $\left.J_{v}=L_{p} \Delta P_{m}\right)$ using DI water, over a transmembrane pressure range of 5.5 - 10.3 bar. Salt rejection was determined for 1,000 $\mathrm{mg} / \mathrm{L} \mathrm{NaCl}$ feed solution at transmembrane pressure of 6.9 bar and a crossflow velocity of 0.18 $\mathrm{m} / \mathrm{s}$. Concentrations of $\mathrm{NaCl}$ in the feed and permeate streams were measured using a conductivity meter (CON 11 Economy Meter, Oakton Instruments, Vernon Hills, IL).

Membrane integrity before and after membrane exposure to free chlorine was assessed via a recently developed marker-based approach ([19], Section 3, Supplementary Material. Briefly, a readily detectable fluorescent molecular marker, uranine (Fisher Scientific, Pittsburgh, PA), was dosed into the RO feed stream by a metering pump (DDA 7.5-16 model, Grundfos Pumps Corporation, Bjerringbro, Denmark) to achieve a $40-\mathrm{mg} / \mathrm{L}$ marker solution in the RO feed. Membrane integrity loss is expected to result in increased marker passage through PA membrane. Thus, the marker concentration in the RO permeate stream was monitored by a fluorescent marker detection system (Ocean Optics, Dunedin, FL), which was installed in-line with the RO permeate stream and had a minimum concentration detection limit of $0.2 \mathrm{ppb}$ for uranine [19]. Characterization of the marker transport and quantification of membrane integrity was carried out via the approach described in Section 3 and in the Supplementary Material. 


\subsection{Membrane Surface Characterization}

Following the membrane integrity tests in which the fluorescent molecular marker approach was utilized (post membrane exposure to free chlorine), the membrane coupons were removed from the RO cell. First, membrane surface wettability was examined via water contact angle measurements using the captive bubble method (Krus Model DSA 100, Hamburg, Germany) with an air volume of $10 \mu \mathrm{L}$. Each reported contact angle represents the average of five replicate measurements. The hydrophilicity was expressed in terms of the free energy of hydration $\left(\Delta G_{i w}\right)$ as per the Young-Dupree equation [31]:

$$
\Delta G_{i w}=-\gamma_{w}\left(1+\cos \theta_{w}\right)
$$

where $\gamma_{w}$ is the surface energy of water $\left(-72.8 \mathrm{~mJ}\right.$ at $\left.20^{\circ} \mathrm{C}\right)$, and $\theta_{w}$ is the water contact angle. The shift from hydrophobicity to hydrophilicity is generally assigned at $\Delta G_{i w}=-113 \mathrm{~mJ} / \mathrm{m}^{2}$ (i.e., $\Delta G_{i w}$ $>-113 \mathrm{~mJ} / \mathrm{m}^{2}$ hydrophilic surface and $\Delta G_{i w}<-113 \mathrm{~mJ} / \mathrm{m}^{2}$ hydrophobic surface), which corresponds to a water contact angle of about $56.5^{\circ}[32]$.

Membrane surface roughness was quantified by tapping mode atomic force microscopy (AFM) (Multimode AFM with Nanoscope IIa SPM controller, Digital Instruments, Santa Barbara, CA) after vacuum drying at room temperature $\left(\sim 22^{\circ} \mathrm{C}\right)$ for at least 24 hours. All AFM scans were taken in ambient air using NSC15 silicon nitride probes (Digital Instruments, Veeco Metrology Group, Santa Barbara, Ca) with a force constant in the range of 20-70 N/m. AFM scans were taken at different 5 locations on the membrane surface. Scans were replicated at the same location at $0^{\circ}$ and $90^{\circ}$ to verify that the AFM scans were free of directional errors. The root-mean-square surface roughness $\left(R_{r m s}\right)$ was determined from the AFM feature height distribution data [32]: 


$$
R_{r m s}=\sqrt{\frac{\sum\left(Z_{i}-Z_{\text {avg }}\right)^{2}}{N}}
$$

where $Z_{i}$ is the surface feature height of the $\mathrm{i}^{\text {th }}$ sample out of $\mathrm{N}$ total samples, and $Z_{\text {avg }}$ is the average feature height.

The intact and oxidized membrane surfaces were also examined by scanning electron microscopy (SEM; JSM-6700F model, JOEL, Tokyo, Japan) post vacuum drying. Membrane samples were first cut into $2 \mathrm{~cm} \times 2 \mathrm{~cm}$ pieces then sputtered with gold nanoparticles at 70 mTorr at $15 \mathrm{~mA}$ for 2 minutes (Anatech Hummer 6.2 Sputtering System, Hayward, CA), to form in a gold film thickness of approximately $10 \mathrm{~nm}$. SEM imaging was obtained at electron beam voltages ranging from 5 to $10 \mathrm{kV}$ at an average working distance of $5.5 \mathrm{~mm}$. The active layer thickness of the ESPA2 membrane was determined from cross-sectional SEM images (JEOL JSM-6700F Field Emission SEM with EDS, Japan) and dual-beam SEM/FIB (Nova 600, FEI Company, Hillsboro, OR) following a previously reported protocol [3] .

Membrane surface elemental analysis was carried out via x-ray photoelectron spectroscopy (XPS; AXIS Ultra DLD, Kratos Analytical, Manchester, U.K.) post vacuum drying. The above analysis provides the kinetic energy of electrons emitted from the surface regime (depth of $\sim 10$ $\mathrm{nm}$ ) [33] thus suitable for elucidating the elemental compositions of the PA active layer. Survey spectra were first taken over the range of $0-1,200 \mathrm{eV}$ and the elemental binding energy was calibrated with the reference energy of carbon $1 \mathrm{~s}$ at $285 \mathrm{eV}$. Atomic concentration percentages of $\mathrm{O}, \mathrm{N}, \mathrm{C}$, and $\mathrm{Cl}$ of the membranes before and after exposure to chlorine were determined from the area under the photoelectron peak using the atomic sensitivity factors of $0.78,0.477,0.278$, and 0.891 for $\mathrm{O} 1 \mathrm{~s}, \mathrm{~N} 1 \mathrm{~s}, \mathrm{C} 1 \mathrm{~s}$, and $\mathrm{Cl} 2 \mathrm{p}$ peaks, respectively. At least 20 scans were taken for each membrane sample. 


\section{Analysis of Effect of Chlorine Exposure on Membrane Solute Transport Parameters, Integrity Loss and Salt Rejection}

\subsection{Marker Transport Parameters and Intrinsic Salt Rejection}

Membrane surface oxidation as well as solute transport through the membrane surface are governed by the solute concentration at the membrane surface $\left(C_{m e m, i}\right)$ which, for a given RO solute feed concentration, can be estimated from the classical film model for concentration polarization $[27,34]$ :

$$
C P_{i}=\frac{C_{m e m, i}-C_{p, i}}{C_{b, i}-C_{p, i}}=\exp \left(\frac{J_{v}}{k_{f, i}}\right)
$$

where subscript $i$ denotes the solute, $J_{v}$ is the total permeate flux, $C_{p, i}$ and $C_{b, i}$ are the solute concentrations in the permeate stream and in the bulk of feed channel (essentially equal to the feed concentration, $C_{f}$, for the present short PFRO channel), respectively, and $k_{f, i}$ is the solute feed-side mass transfer coefficient. In the present analysis, the marker concentration at the membrane surface $\left(C_{m e m, m}\right)$ was assumed to be essentially the same for both intact and oxidized membranes, which is a reasonable simplification as long as the marker permeation flux is not excessive, but sufficient to affect marker concentration in the permeate. The mass transfer coefficient for the marker (uranine), $k_{f, m}$, was determined, based on a series of experiments in which the permeate flux was varied (through adjustment of the transmembrane pressure), at a constant marker feed dose, using the following relationship [35]:

$$
\ln \left(J_{v} \frac{1-R_{o, m}}{R_{o, m}}\right)=\ln B+\frac{J_{v}}{k_{f, m}}
$$

in which $B$ is the membrane marker permeability coefficient, and $R_{o, m}$ is the observed marker rejection $\left(=1-C_{p, m} / C_{f, m ;}\right.$ where $C_{p, m}$ and $C_{f, m}$ are the marker permeate and feed concentrations, 
respectively). The RHS of Eq. 4 should vary linearly with $J_{v}$, for a given crossflow velocity, and thus allows determination of both $B$ and $k_{f, m}$ from the intercept and slope of the linear relationship, respectively. In the rectangular PFRO channel, it is reasonable to expect that the mass transfer coefficient for a given solute $i, k_{f, i} \propto D_{i}^{2 / 3}$ (where $D_{i}$ is the molecular mass diffusivity for solute $i$ ) as has been shown in various experimental and theoretical studies [27], where $D_{i}$ is the solute mass diffusivity. Given the experimentally determined marker mass transfer coefficient, those for $\mathrm{NaCl}$ and $\mathrm{NaOCl}$ were estimated from $k_{f, i}=\left(k_{f, m}\right)\left(D_{m} / D_{i}\right)^{2 / 3}$. At the experimental temperature $\left(20^{\circ} \mathrm{C}\right)$, the diffusion coefficients for the above were estimated from empirical relationships in $[27,36]$ to be $1.47 \times 10^{-9} \mathrm{~m}^{2} / \mathrm{s}$ and $1.99 \times 10^{-9} \mathrm{~m}^{2} / \mathrm{s}$, respectively. The diffusion coefficient of uranine was estimated to be $5.14 \times 10^{-10} \mathrm{~m}^{2} / \mathrm{s}$ via the Hayduk and Laudie's diffusion coefficient correlation for nonelectrolytes in dilute aqueous solutions [37] where the molar volume was obtained from molecular modeling using HyperChem software package [38].

Membrane transport parameters for marker passage through the membrane were determined from application of the Kedem-Katchalsky model [39]:

$$
J_{v} C_{p, m}=B\left(C_{m e m, m}-C_{p, m}\right)+(1-\sigma) J_{v}\left(\frac{C_{m e m, m}+C_{p, m}}{2}\right)
$$

in which $C_{p, m}$ and $C_{m e m, m}$ are the marker concentration in the RO permeate and at the membrane surface, respectively, and $\sigma$ is its reflection coefficient. Marker transport through an intact membrane is governed by solution-diffusion with negligible solute convective transport such that $\sigma \rightarrow 1$. However, upon membrane integrity loss (e.g., due to membrane degradation), one would expect increased contribution of marker passage through breached areas. Therefore, $B$ and $\sigma$ should increase and decrease, respectively, as a consequence of membrane integrity loss. The 
parameters, $B$ and $\sigma$, associated with marker passage through the intact and compromised membranes can be determined based on Eq. 5 as detailed in Section S1 (Supplementary Material). Finally, the influence of membrane oxidation on the intrinsic salt $(\mathrm{NaCl})$ rejection $\left(R_{i n t, N a C l}\right)$ was determined from

$$
R_{i n t, \mathrm{NaCl}}=1-\frac{C_{p, \mathrm{NaCl}}}{C_{m e m, \mathrm{NaCl}}}
$$

where $C_{p, \mathrm{NaCl}}$ and $C_{m e m, \mathrm{NaCl}}$ are the salt concentrations in the permeate and at the membrane surface, respectively, the latter estimated from Eq. 3.

\subsection{Estimation of the extent of Membrane Integrity Loss}

In order to characterize the extent of membrane integrity loss, was quantified in terms of an "equivalent breach size" (i.e., a "pinhole" of a given size). Accordingly, a hindered pore transport model $[40,41]$ was adopted whereby a membrane breach is modeled as a cylindrical

pore located between the membrane feed and permeate sides. Details of the approach and working equations are provided in the Supplementary Material (Section S2). Briefly, rejection ( $R_{\text {marker }}$ ) of a solute (assumed to be spherical in the present analysis) by the pore is dependent on the solute flux and the solute size relative to the pore size $(\lambda)$ and solute transport is restricted by the presence of the pore walls. Solute rejection $\left(R_{\text {marker }}\right)$ by the pore is then expressed as $[40,41]$ :

$$
R_{\text {mar } \mathrm{ker}}=1-\frac{\Phi K_{c}}{1-\exp (-P e)\left(1-\Phi K_{c}\right)}
$$

in which $\Phi$ is a distribution coefficient defined as the ratio of the average solute concentration in the pore to the solute concentration at the membrane surface given as $2(1-\lambda)^{2}$ (Section S2, Supplementary Material). The axial drag factor due to the pore walls and the enhanced drag due 
to the pore walls (which increases the drag on solute diffusion in the radial direction) are denoted by $K_{c}$ and $K_{d}$ irrespectively, and $P e$ is the Peclet number:

$$
P e=\frac{K_{c}\langle V\rangle L}{K_{d} D_{m}}
$$

where $\langle V\rangle$ is the average permeate velocity through the pore, and $L$ is the pore length. In the present quantification of an equivalent breach size, it is convenient to set the pore length to the average thickness of the active PA layer (typically $\sim 100-300 \mathrm{~nm}$ in thin film composite polyamide membranes [1]]). In the present work, the ESPA2 active layer average thickness was estimated (Section 2.5) to be $\sim 200 \mathrm{~nm}$. It is important to emphasize that $\Phi, K_{c}$ and $K_{d}$ are analytic functions of $\lambda$ [42] (determined for a given $\lambda$ via Eq. S6 and S7 (Supplementary Material2). Once the marker rejection is determined, Eq.7 is solved to obtain $\lambda$ and the equivalent breach size (see Supplementary Material).

\section{Results and Discussion}

\subsection{Impact of Chlorine Exposure on Membrane Surface Properties}

As a result of exposure to chlorine, there was a marked change in the elemental composition of the PA membrane surface, as well as well as the presence of $\mathrm{C}-\mathrm{Cl}$ bonds as ascertained from XPS surface analysis (Fig. 2 and 3). Chlorine was not detected on the PA membrane surface prior to chlorine exposure, while approximately 1.4 to $2 \%$ of chlorine content was detected after membrane exposure to 50 to $200 \mathrm{mg} / \mathrm{L}$ of $\mathrm{NaOCl}$ solution for 2.5 to 10 hours. The presence of chlorine in the membrane surface layer is consistent with the expected PA ring chlorination where chlorine ions covalently bond to carbon atoms in the PA ring [15]. Deconvolution of the XPS chlorine peak (Fig. 3) of the chlorinated PA membrane (exposed to $200 \mathrm{mg} / \mathrm{L}$ of $\mathrm{NaOCl}$ chlorine solution for 10 hours) revealed the contribution of three different chlorine peaks. The 
shift in the chlorine peak, associated with the $\mathrm{C}-\mathrm{Cl}$ bonds (both $\mathrm{C}-\mathrm{Cl} 2 \mathrm{p}^{3 / 2}$ and $\mathrm{C}-\mathrm{Cl} 2 \mathrm{p} 1 / 2$ ) confirmed covalent bonding between $\mathrm{Cl}^{-}$and carbon atoms in the PA ring.

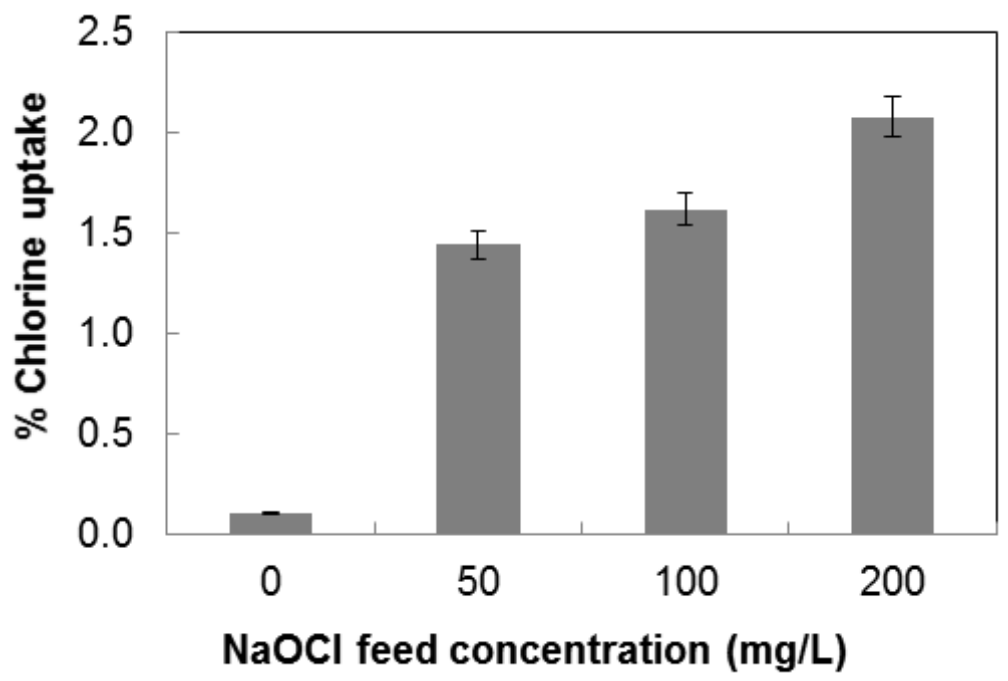

Figure 2. Percent chlorine uptake by PA membrane surface quantified via XPS before and after membrane exposure to chlorine feed solution $(50-200 \mathrm{mg} / \mathrm{L} \mathrm{NaOCl})$ for 10 hours. (Note: $\mathrm{CP}=1.24$ for the RO system operating conditions of $J_{v}=9.3 \times 10^{-6} \mathrm{~m} / \mathrm{s}$ and cross flow velocity of $0.18 \mathrm{~cm} / \mathrm{s}$ ).
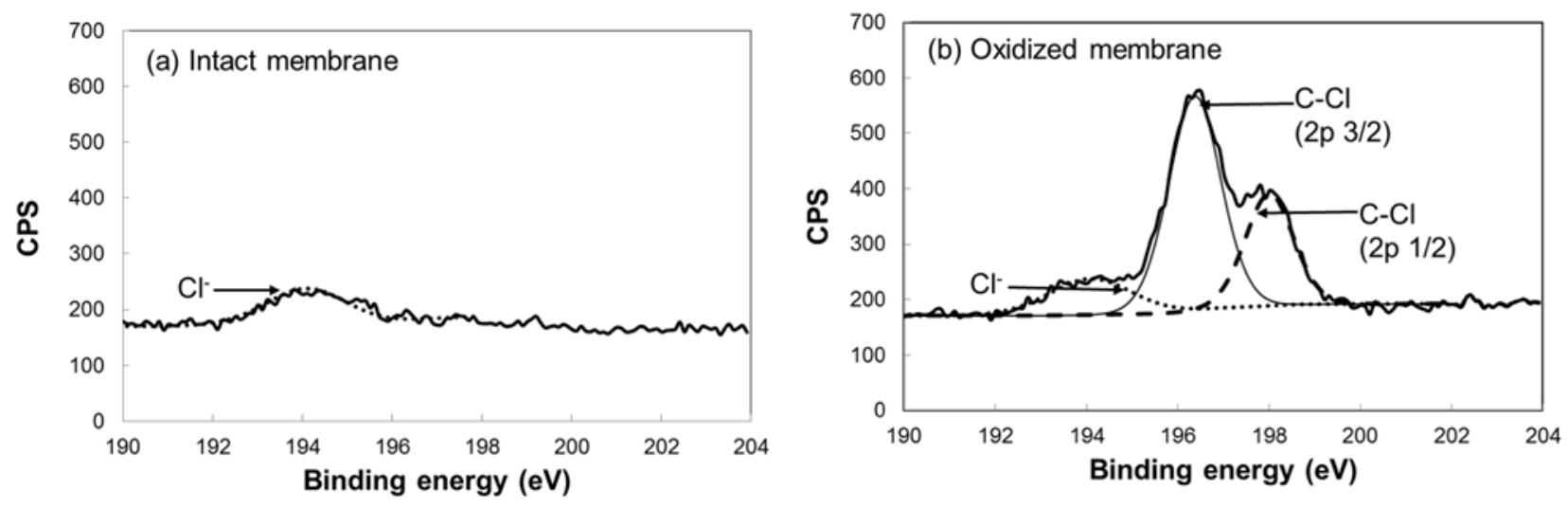

Figure 3. High resolution XPS spectra and deconvoluted peaks assignment of $\mathrm{Cl} 2 \mathrm{p}$ for intact and oxidized PA membranes following exposure to $200 \mathrm{mg} / \mathrm{L} \mathrm{NaOCl}$ feed solution for 10 hours (Note: $\mathrm{CP}=1.24$ for the RO system operation during chlorine exposure at $J_{v}=9.3 \times 10^{-6} \mathrm{~m} / \mathrm{s}$ and cross flow velocity of $0.18 \mathrm{~cm} / \mathrm{s})$. 


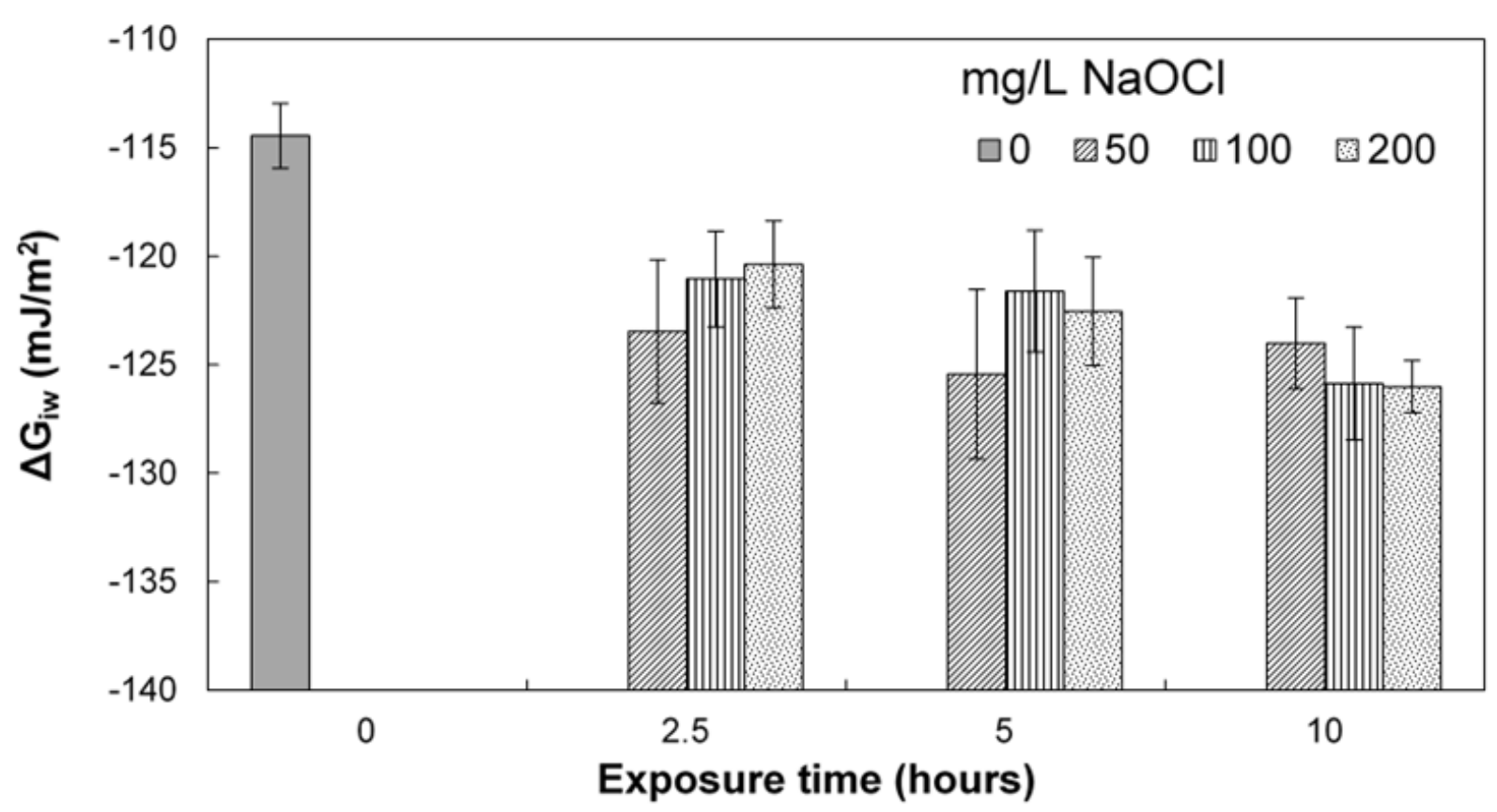

Figure 4. Free energy of hydration for PA membrane surface before and after exposure to $50-200 \mathrm{mg} / \mathrm{L}$ $\mathrm{NaOCl}$ feed solution for 2.5-10 hours. (Note: $\mathrm{CP}=1.24$ for the $\mathrm{RO}$ system operation during chlorine exposure at $J_{v}=9.3 \times 10^{-6} \mathrm{~m} / \mathrm{s}$ and cross flow velocity of $0.18 \mathrm{~cm} / \mathrm{s}$ ).

Previous studies have reported that surface wettability (or hydrophilicity) is impacted by physicochemical characteristics of the surface material [24, 32, 43]. Since the free energy of hydration is highly dependent on surface chemistry [32], one would expect that chlorination of the PA surface could increase the free energy of hydration and thus increase surface hydrophilicity as is shown in Fig. 4. Following exposure to aqueous chlorine solution, the membrane water contact angle decreased by $9.1-23.6 \%$ (from $\sim 55^{\circ}$ to $42-50^{\circ}$ ), which corresponded to 5.2-9.6\% decrease in the free energy of hydration $\left(\Delta G_{i w}\right)$ (Fig. 4). The intact and oxidized membranes $\Delta G_{i w}$ values were below $-113 \mathrm{~mJ} / \mathrm{m}^{2}$, indicating that the PA membrane surfaces became hydrophilic, with lower $\Delta G_{i w}$ attributed to increased surface hydrophilicity following exposure to chlorine. However, for the present range of experimental exposure 
conditions there was no apparent correlation of $\Delta G_{i w}$ with $\mathrm{NaOCl}$ chlorine feed concentration (50-200 mg/L) or exposure time (2.5-10 hours).

Analysis of membrane surface topography, before and after chlorination (Fig. 5) showed a large deviation in surface peaks separation distance (dictating the geometry of surface "valleys") and membrane surface feature heights following membrane chlorine exposure. Increased surface roughness $\left(R_{r m s}\right)$ by up to $\sim 27 \%$ was observed (from $\sim 70 \mathrm{~nm}$ to $88 \mathrm{~nm}$ ) upon exposure of the intact membrane to $200 \mathrm{mg} / \mathrm{L} \mathrm{NaOCl}$ for 10 hours. It is generally reported that increased surface roughness for hydrophobic surfaces is accompanied by increased surface hydrophobicity [43]. However, the PA membrane exposure to chlorine resulted in decreased $\Delta G_{i w}$ (Fig. 6) indicating increased surface hydrophilicity. For example, membrane exposure to 100 and $200 \mathrm{mg} / \mathrm{L} \mathrm{NaOCl}$ solution for 10 hour, demonstrated $\Delta G_{i w}$ decrease by $7.6 \%$ and $8.3 \%$, respectively, while the surface roughness correspondingly increased by $\sim 23 \%$ and $27 \%$. The above behavior could be attributed to the unbalanced dipole moments induced at the surface chains due to surface chlorination and thus increased hydrophilicity [22]. 

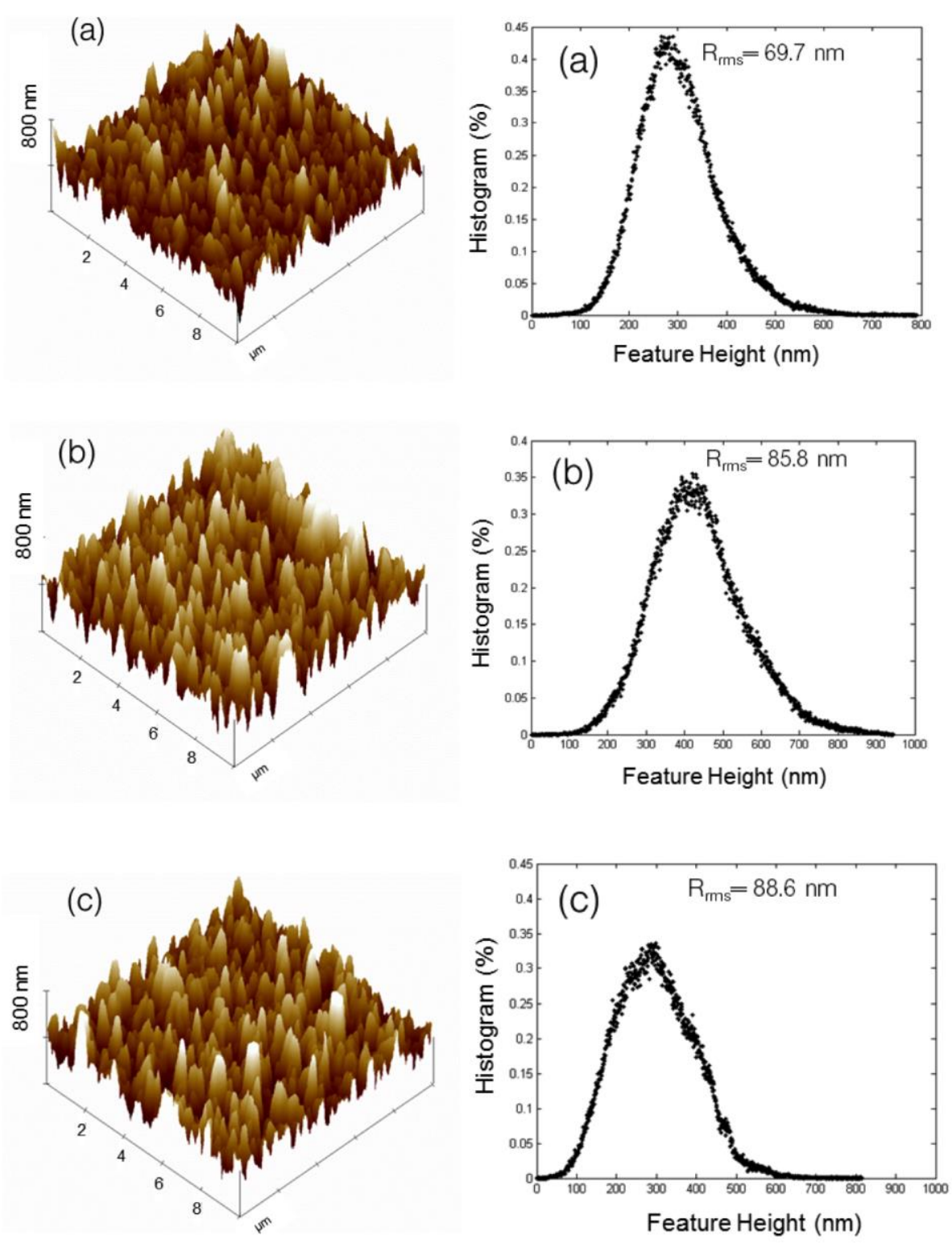

Figure 5. Topography and feature height distributions (obtained via AFM) for (a) intact PA membrane, (b) PA membrane exposed to $100 \mathrm{mg} / \mathrm{L} \mathrm{NaOCl}$ feed solution for 10 hours, and (c) PA membrane exposed to $200 \mathrm{mg} / \mathrm{L} \mathrm{NaOCl}$ feed solution for 10 hours. (Note: $\mathrm{CP}=1.24$ for the $\mathrm{RO}$ system operation during chlorine exposure at $J_{v}=9.3 \times 10^{-6} \mathrm{~m} / \mathrm{s}$ and cross flow velocity of $0.18 \mathrm{~cm} / \mathrm{s}$ ). 


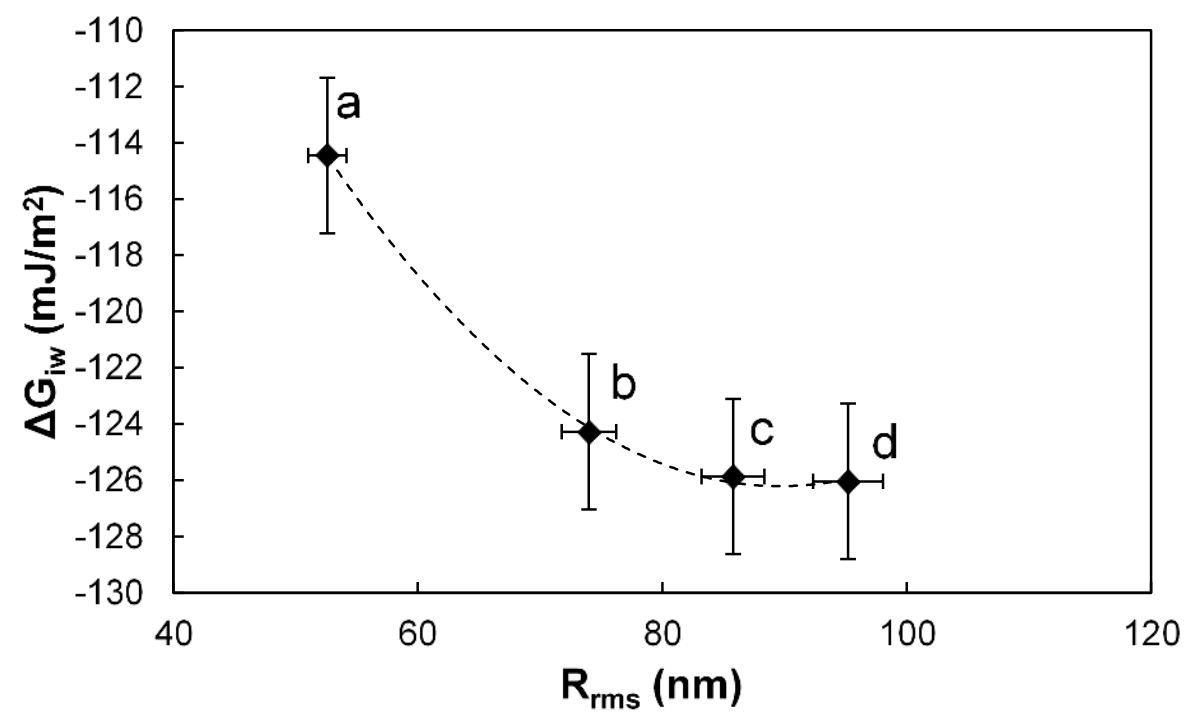

Figure 6. Free energy of hydration $\left(\Delta G_{i w}\right)$ of the intact PA membrane (a) decreased with increasing PA membrane surface roughness $\left(R_{r m s}\right)$ after exposure to (b) 50, (c) 100 , and (d) $200 \mathrm{mg} / \mathrm{L} \mathrm{NaOCl}$ feed solution for 10 hours. (Note: $\mathrm{CP}=1.24$ for the $\mathrm{RO}$ system operation during chlorine exposure at $J_{v}=9.3 \times 10^{-6} \mathrm{~m} / \mathrm{s}$ and cross flow velocity of $0.18 \mathrm{~cm} / \mathrm{s}$ ).

\subsection{Impact of PA Membrane Chlorine Exposure on Performance Degradation}

The impact of membrane exposure to chlorine on membrane performance degradation was

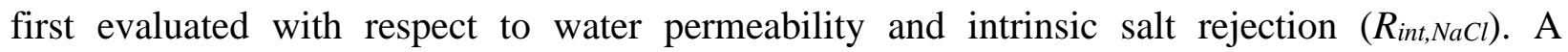
measurable water permeability increase of 3-15\% was observed following membrane surface exposure to 50-200 mg/L NaOCl chlorine concentration and 2.5 - $10 \mathrm{hr}$ exposure period (Fig. 7). The above water permeability increase was consistent with increased membrane surface hydrophilicity and roughness (Figs. 4 and 5). Chlorine exposure lowered the intrinsic salt ( $\mathrm{NaCl})$ rejection (Fig. 8) from 99.2 to $97.4 \%$, for the present range of chlorine exposure period (2.5-10 hr) and concentration (50-200 mg/L). There was a clear degradation of salt rejection with both increased concentration and exposure time, a decline of significance when considering the impact on high rejection membranes. It is important to recognize, however, that monitoring of 
water permeability and/or salt passage is of insufficient accuracy to unambiguously discern and quantify the trends as a function of exposure time and concentration (Figs. S2 and S5, Supplementary Material).

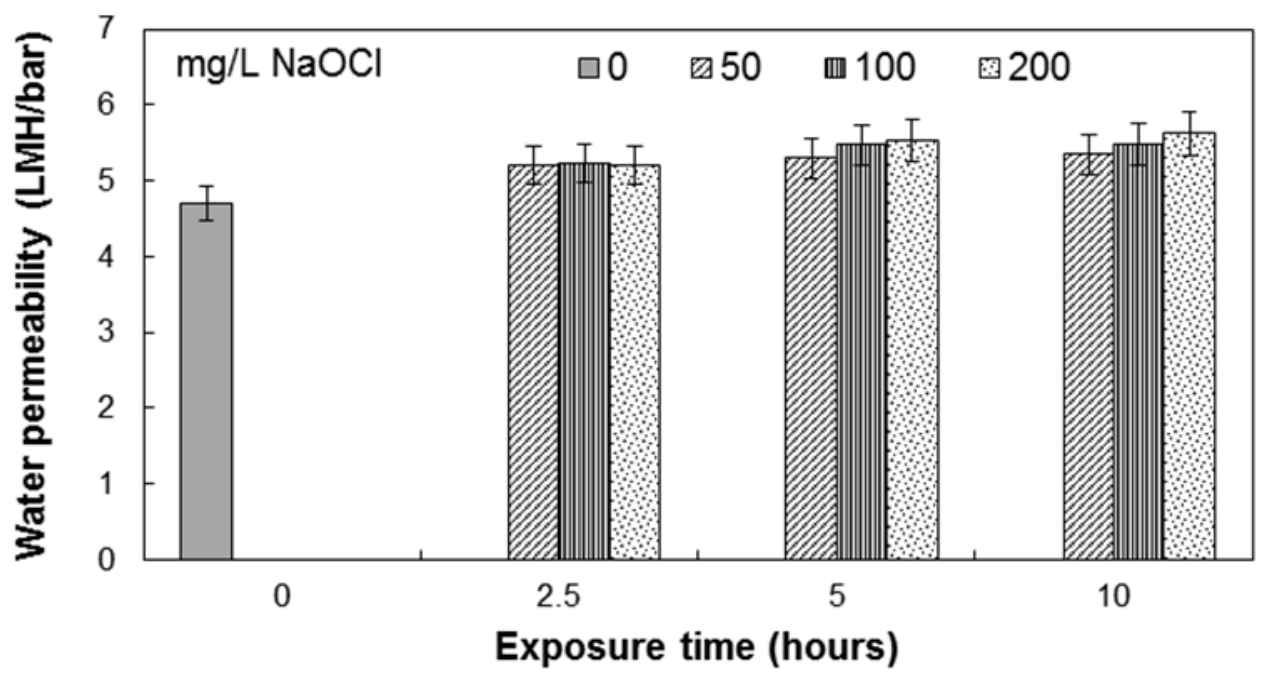

Figure 7. Water permeability (DI water) of PA membrane before and after exposure to $50-200 \mathrm{mg} / \mathrm{L}$ $\mathrm{NaOCl}$ feed solution for 2.5-10 hours. (Note: $\mathrm{CP}=1.24$ for the $\mathrm{RO}$ system operation during chlorine exposure at $J_{v}=9.3 \times 10^{-6} \mathrm{~m} / \mathrm{s}$ and cross flow velocity of $0.18 \mathrm{~cm} / \mathrm{s}$ ).

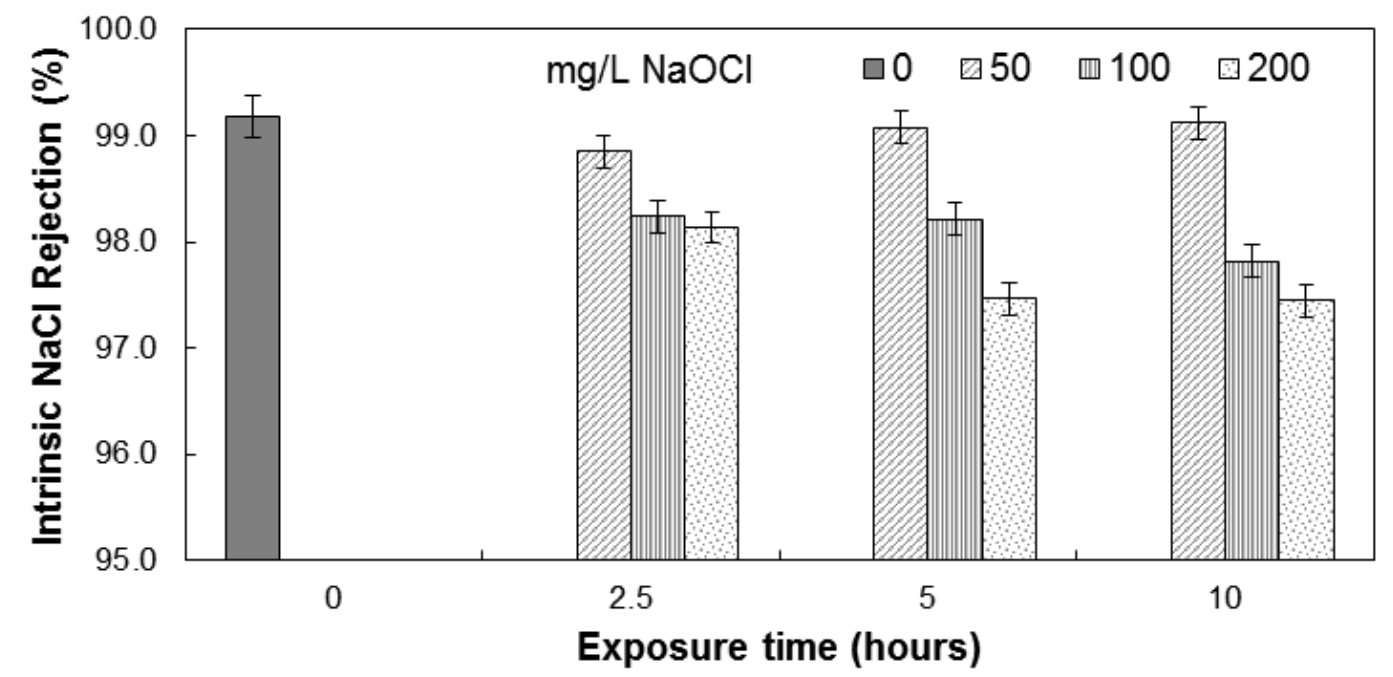

Figure 8. Intrinsic salt rejection by PA membrane before and after exposure to $50-200 \mathrm{mg} / \mathrm{L} \mathrm{NaOCl}$ feed solution for 2.5-10 hours. (Note: $\mathrm{CP}=1.24$ for the RO system operation during chlorine exposure at $J_{v}=$ $9.3 \times 10^{-6} \mathrm{~m} / \mathrm{s}$ and cross flow velocity of $\left.0.18 \mathrm{~cm} / \mathrm{s}\right)$. 

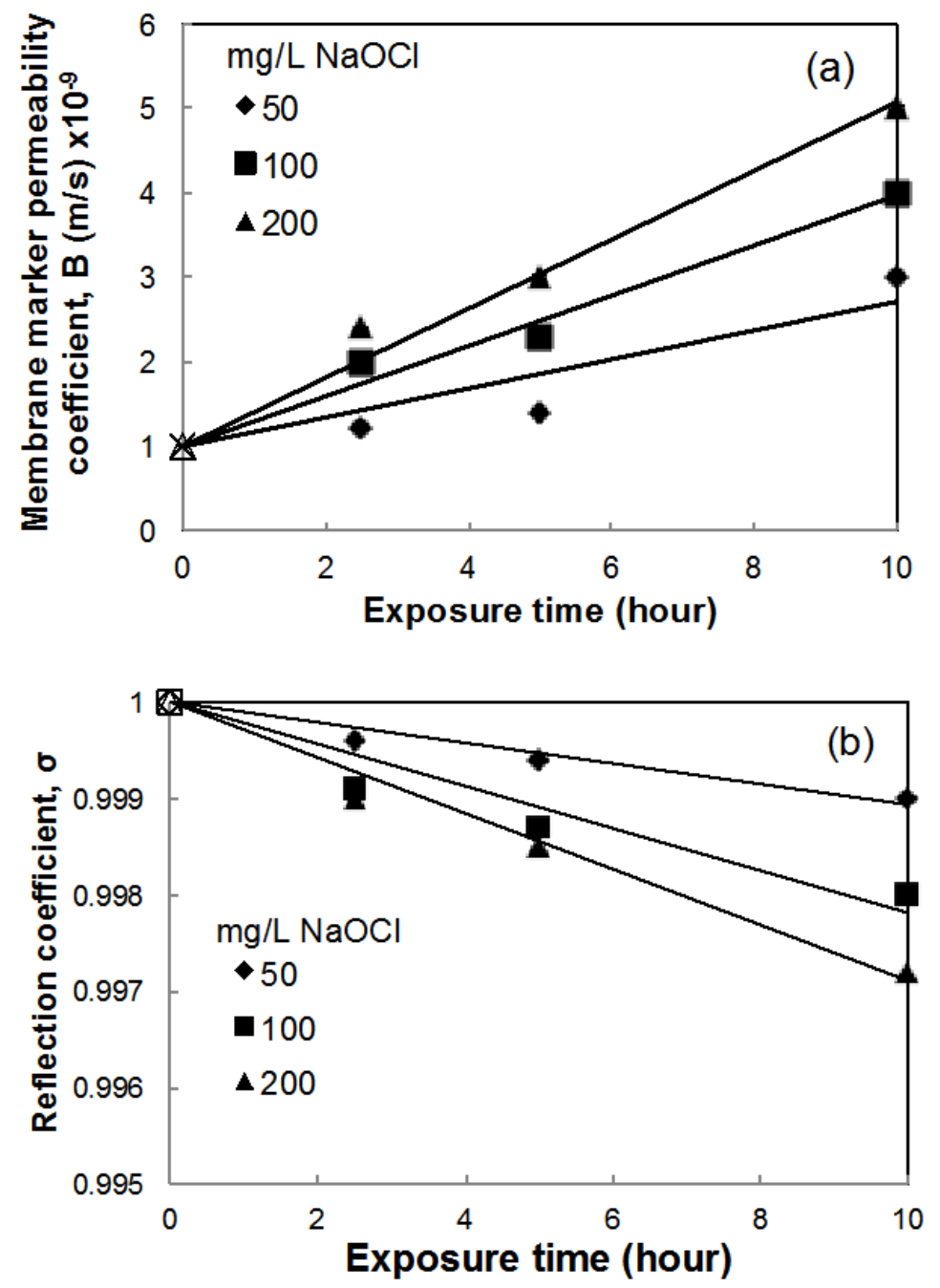

Figure 9. Membrane marker permeability coefficient $(B)$ and reflection coefficient $(\sigma)$ of the PA membrane before and after exposure to $50-200 \mathrm{mg} / \mathrm{L} \mathrm{NaOCl}$ feed solution for $2.5-10$ hours. $B$ and $\sigma$ were determined from the marker permeate concentration in response to a constant $40-\mathrm{mg} / \mathrm{L}$ marker feed dose (Section 2.4). (Note: $\mathrm{CP}=1.24$ for the RO system operation during chlorine exposure at $J_{v}=9.3 \times 10^{-6} \mathrm{~m} / \mathrm{s}$ and cross flow velocity of $0.18 \mathrm{~cm} / \mathrm{s}$ ).

The impact of membrane exposure to chlorine was also explored by quantifying the membrane transport parameters $(B$ and $\sigma$ ) for the uranine molecular fluorescent marker (Section 3.1, Eq. 5, Eq. S1, Section S2, Supplementary Material). Given the high level of marker 
detection for uranine (down to $0.2 \mathrm{ppb}$ ), the marker's $B$ and $\sigma$ values were determined to within an error of at most $2 \%$ and $0.04 \%$, respectively. As sown in Fig. 9a, following chlorine exposure, the value of $B$ increased with both exposure time and chlorine concentration by $10-450 \%$ over the range of $100-2000 \mathrm{ppm}$-hr chlorine exposure, while over the same exposure conditions $\sigma$ decreased slightly by $0.1-0.3 \%$ (Fig. 9b). It is evident that the marker $B$ and $\sigma$ correlated with increased chlorine exposure time (up to $10 \mathrm{~h}$ ) and concentration (50-200 $\mathrm{mg} / \mathrm{L}$ chlorine), the former showing a somewhat stronger correlation (Fig. 9). It is emphasized that, although the decline in $\sigma$ was relatively small $(<3 \%)$ it was manifested by a significant permeate marker concentration increase (as high as $\sim 30-40 \%$ for the present range of conditions) as can be ascertained from Eq.5. It is noted that the above changes in the marker $B$ and $\sigma$ signify that marker passage via diffusion (Eq. 5) was about $28 \%-40 \%$ of the total passage, the remainder attributed to convective transport through the membrane. Here it is important to note that since the salt transport parameter was about an order of magnitude higher than for the marker, resolving the impact of exposure time and concentration based on salt passage data was infeasible (Figs. S2 and S5, Supplementary Material).

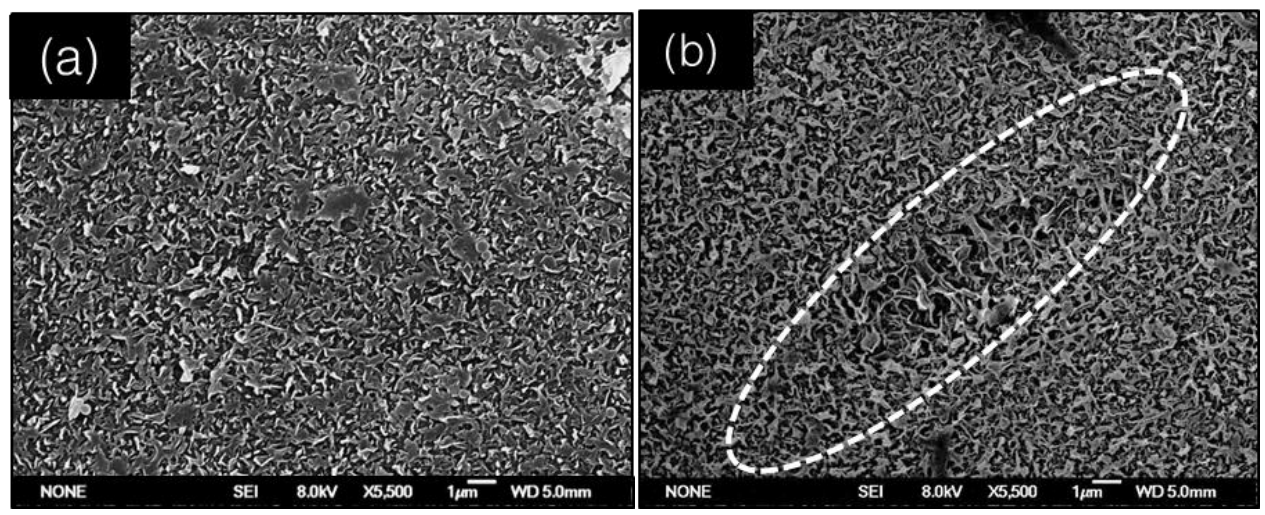

Figure 10. SEM images of PA membrane surface (a) before and (b) after exposure to chlorine solution (200 mg/L NaOCl) for ten hours. An area of evident membrane surface degradation is circled in white. 
Increased marker passage upon membrane exposure to chlorine was consistent with physical membrane surface damage (or integrity loss) as illustrated in Fig. 10 for 10 hour exposed to 248 $\mathrm{mg} / \mathrm{L}$ chlorine concentration. The breached area may have developed, in part, due to decreased tensile strength of the PA layer following membrane exposure to chlorine, as reported in previous studies [23]. The breached areas were non-uniformly distributed throughout the membrane surface and their presence was indicative with integrity loss consistent with the alteration of membrane performance (e.g., increased solute passage and increased permeability; Figs. 7-9).

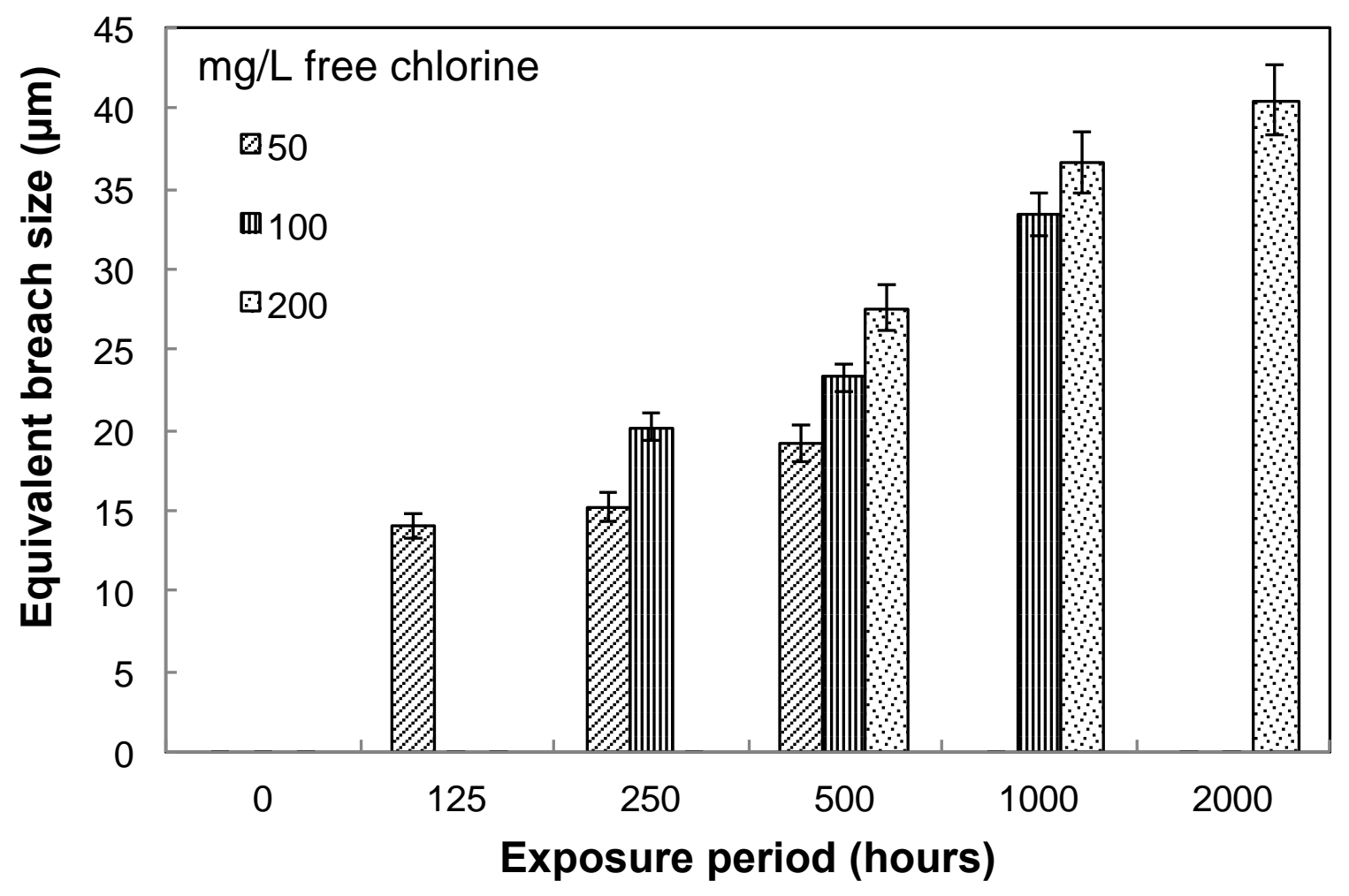

Figure 11. Equivalent breach size for PA membrane before and after exposure to $50-200 \mathrm{mg} / \mathrm{L} \mathrm{NaOCl}$ feed solution for 2.5-10 hours. Chlorine exposure is expressed in terms of the commonly-used unit of ppm-hour (product of chlorine concentration and exposure period). (Note: $\mathrm{CP}=1.24$ for the RO system operation during chlorine exposure at $J_{v}=9.3 \times 10^{-6} \mathrm{~m} / \mathrm{s}$ and cross flow velocity of $0.18 \mathrm{~cm} / \mathrm{s}$ ). 


\subsection{Severity of Membrane Integrity Loss}

The severity of membrane integrity loss upon oxidation (Fig. 11), as quantified by the equivalent breach size, was in the range of 13.8 to $39.2 \mu \mathrm{m}$, for the present range of chlorine exposure period (2.5-10 hours) at $\mathrm{NaOCl}$ concentration $(50-200 \mathrm{mg} / \mathrm{L}$ feed or $62-248 \mathrm{mg} / \mathrm{L}$ at the membrane surface). The equivalent breach size increased with chlorine exposure intensity as represented by ppm-hour (Fig. 11). For example, the equivalent breach size increased by a factor of 1.84 as membrane exposure to chlorine increased from 125 ppm-hour to 2,000 ppm-hour (or 155-2,480 ppm-hour on the basis of chlorine concentration at the membrane surface). Increased equivalent breach size correlated with increased $B$ and decreased $\sigma$ (Fig. 12), suggesting increased level of marker solution-diffusion and convection as membrane integrity loss became more severe. It is cautioned that the equivalent breach size metric is not offered as an indication of the potential passage of micropollutants (e.g., pathogens). However, when the equivalent breach size is no larger than the size of the marker size or micropollutant of concern a reasonable conservative deduction is that passage of larger species is a low probability. Here it is noted that the potential for micropollutants passage could be assessed, without loss of generality, using larger fluorescent markers following the same approach as demonstrated in the present work.

While it appears that the commonly-used ppm-hour metric of chlorine exposure is somewhat correlated with breach severity, there is a measurable difference $(10 \%-32 \%)$ in the equivalent breach size among the oxidized membranes for the same ppm-hour exposure (Fig. 12). For the same ppm-hour exposure, higher chlorine exposure condition resulted in larger equivalent breach size. The latter behavior is exemplified for 500 ppm-hour chlorine exposure (or 620 ppm-hr on the basis of chlorine concentration at the membrane surface) where the equivalent breach size was $23.5 \%$ greater for exposure to chlorine at $100 \mathrm{mg} / \mathrm{L}(124 \mathrm{mg} / \mathrm{L}$ at the membrane surface) relative to $50 \mathrm{mg} / \mathrm{L}(62 \mathrm{mg} / \mathrm{L}$ at the membrane surface). On the other hand, increasing the 
exposure time to chlorine from 2.5 to 10 hours for $100 \mathrm{mg} / \mathrm{L}(124 \mathrm{mg} / \mathrm{L}$ at the membrane surface) solution (250-1,000 ppm-hour or correspondingly 310-1,240 ppm-hr chlorine concentration at the membrane surface) resulted in only $45 \%$ increase in the equivalent breach size (Fig. 11).
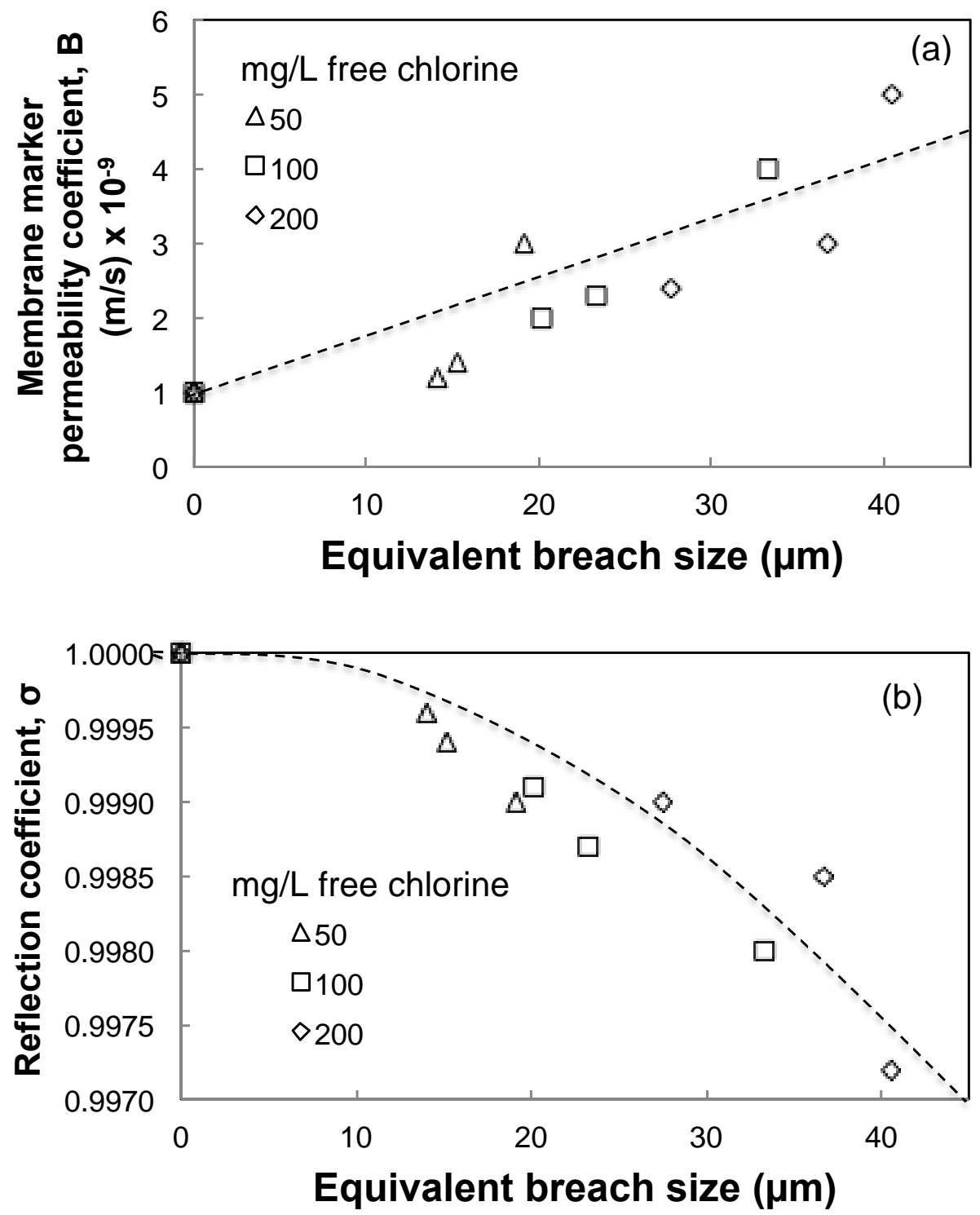

Figure 12. Variation of (a) membrane marker transport parameter $(B)$, and (b) reflection coefficient $(\sigma)$ with equivalent breach size for PA membrane before and after membrane exposure to $50-200 \mathrm{mg} / \mathrm{L}$ $\mathrm{NaOCl}$ feed solution for periods of 2.5-10 hours. (Note: $\mathrm{CP}=1.24$ for the RO system operation during chlorine exposure at $J_{v}=9.3 \times 10^{-6} \mathrm{~m} / \mathrm{s}$ and cross flow velocity of $0.18 \mathrm{~cm} / \mathrm{s}$ ). 
The non-uniqueness of ppm-hr of chlorine exposure, as metric for setting a limit on membrane exposure to chlorine, was further exemplified by noting that after low chlorine exposure of about $5 \mathrm{mg} / \mathrm{L}$ (within the range often encountered in RO plants [20, 21]) for 100 hours (i.e. 500 ppm-hr chlorine exposure), there was no loss of membrane integrity; however, at much high chlorine concentration $(50-100 \mathrm{mg} / \mathrm{L})$ and the same $500 \mathrm{ppm}-\mathrm{hr}$ chlorine exposure measureable loss of membrane integrity and thus performance were observed (Fig. 11). The above results suggest that the commonly-used ppm-hour metric to represent chlorine exposure (which gives equal weight to chlorine exposure concentration and time), although providing a reasonable guide for avoiding excessive chlorine exposure conditions, may not be an accurate (or sufficient) representation of chlorine exposure conditions with respect to the expected severity of membrane integrity loss.

\section{Conclusions}

The impact of exposure of polyamide (PA) reverse osmosis (RO) membrane to chlorine was evaluated with respect to alteration of surface properties, membrane performance degradation and integrity deterioration. Membrane exposure to chlorine (50-200 mg/L of $\mathrm{NaOCl}$ solution) for varying exposure periods (2.5 - 10 hours) in a plate-and-frame RO system revealed measurable increase in membrane water permeability $(3 \%-15 \%)$ and reduced salt rejection (from $99.2 \%$ for the intact membrane to as low as $97.4 \%$ ). Although membrane surface roughness increased with the intensity of chlorine exposure (as quantified by the common ppm-hr chlorine exposure metric), the surface energy of hydration decreased by $5.2-9.6 \%$ indicating increased surface hydrophilicity. Analysis of fluorescent marker (i.e., uranine) transport, via the solution-diffusion transport model, demonstrated that, over the range of chlorine exposure intensity of 125- 2000 ppm-hr, the membrane marker permeability coefficient $(B)$ rose by up to a factor of $\sim 5$ while the 
reflection coefficient decreased slightly from essentially unity to 0.997 . The influence of chlorine exposure on marker passage was quantified as being due to an equivalent cylindrical breach which was in the size range of $\sim 14-40 \mu \mathrm{m}$ for the range of chlorine exposure conditions in the present study. Although the level of membrane integrity loss/performance degradation reasonably correlated with the common ppm-hr metric of chlorine exposure, it is stressed that, for the same ppm-hr exposure, the severity of membrane integrity degradation increased for higher exposure concentrations. Results of the present work suggest that the marker based approach can serve to characterize the severity of membrane integrity loss in relation to the observed loss of performance in terms of both water permeability and salt rejection.

\section{ACKNOWLEDGEMENTS}

This work was supported, in part, by the Water Technology Research (WaTeR) Center at the University of California, Los Angeles (UCLA), California Department of Water Resources, Water Reuse Research Foundation and UCLA Dissertation Year Fellowship awarded to Sirikarn Surawanvijit. The presented material is based upon research performed in a renovated laboratory by the National Science Foundation under Grand No. 0963183, which is an award funded under the American Recovery and Reinvestment Act of 2009 (ARRA). 


\section{REFERENCES}

[1] K.P. Lee, T.C. Arnot, D. Mattia, A review of reverse osmosis membrane materials for desalinationDevelopment to date and future potential, Journal of Membrane Science, 370 (2011) 1-22.

[2] B.C. McCool, A. Rahardianto, J. Faria, K. Kovac, D. Lara, Y. Cohen, Feasibility of reverse osmosis desalination of brackish agricultural drainage water in the San Joaquin Valley, Desalination, 261 (2010) 240-250.

[3] J. Thompson, N. Lin, E. Lyster, R. Arbel, T. Knoell, J. Gilron, Y. Cohen, RO membrane mineral scaling in the presence of a biofilm, Journal of Membrane Science, 415-416 (2012) 181-191.

[4] J.J. Schoeman, A. Steyn, Nitrate removal with reverse osmosis in a rural area in South Africa, Desalination, 155 (2003) 15-26.

[5] C. Fritzmann, J. Löwenberg, T. Wintgens, T. Melin, State-of-the-art of reverse osmosis desalination, Desalination, 216 (2007) 1-76.

[6] C.R. Martinetti, A.E. Childress, T.Y. Cath, High recovery of concentrated RO brines using forward osmosis and membrane distillation, Journal of membrane science, 331 (2009) 31-39.

[7] J. Thompson, A. Rahardianto, H. Gu, M. Uchymiak, A. Bartman, M. Hedrick, D. Lara, J. Cooper, J. Faria, P.D. Christofides, Y. Cohen, Rapid field assessment of RO desalination of brackish agricultural drainage water, Water Research, 47 (2013) 2649-2660.

[8] J.S. Vrouwenvelder, D. van der Kooij, Diagnosis, prediction and prevention of biofouling of NF and RO membranes, Desalination, 139 (2001) 65-71.

[9] H.C. Flemming, G. Schaule, T. Griebe, J. Schmitt, A. Tamachkiarowa, Biofouling - the Achilles heel of membrane processes, Desalination, 113 (1997) 215-225.

[10] I.C. Tessaro, J.B.A. da Silva, K. Wada, Investigation of some aspects related to the degradation of polyamide membranes: aqueous chlorine oxidation catalyzed by aluminum and sodium laurel sulfate oxidation during cleaning, Desalination, 181 (2005) 275-282.

[11] N. Prihasto, Q.-F. Liu, S.-H. Kim, Pre-treatment strategies for seawater desalination by reverse osmosis system, Desalination, 249 (2009) 308-316.

[12] C.J. Gabelich, J.C. Frankin, F.W. Gerringer, K.P. Ishida, I.H. Suffet, Enhanced oxidation of polyamide membranes using monochloramine and ferrous iron, Journal of Membrane Science, 258 (2005) 64-70.

[13] J. Glater, S.-k. Hong, M. Elimelech, The search for a chlorine-resistant reverse osmosis membrane, Desalination, 95 (1994) 325-345.

[14] G.-D. Kang, C.-J. Gao, W.-D. Chen, X.-M. Jie, Y.-M. Cao, Q. Yuan, Study on hypochlorite degradation of aromatic polyamide reverse osmosis membrane, Journal of Membrane Science, 300 (2007) $165-171$.

[15] J. Glater, M.R. Zachariah, S.B. McCray, J.W. McCutchan, Reverse osmosis membrane sensitivity to ozone and halogen disinfectants, Desalination, 48 (1983) 1-16.

[16] W.R. Adams, The effects of chlorine dioxide on reverse osmosis membranes, Desalination, 78 (1990) 439-453.

[17] M.K. da Silva, I.C. Tessaro, K. Wada, Investigation of oxidative degradation of polyamide reverse osmosis membranes by monochloramine solutions, Journal of Membrane Science, 282 (2006) 375-382.

[18] A. Ettori, E. Gaudichet-Maurin, J.-C. Schrotter, P. Aimar, C. Causserand, Permeability and chemical analysis of aromatic polyamide based membranes exposed to sodium hypochlorite, Journal of Membrane Science, 375 (2011) 220-230.

[19] S. Surawanvijit, J. Thompson, A. Rahardianto, V. Frenkel, Y. Cohen, Pulsed marker method for realtime detection of reverse osmosis membrane integrity loss, Desalination, 370 (2015) 25-32.

[20] H. Shemer, R. Semiat, Impact of halogen based disinfectants in seawater on polyamide RO membranes, Desalination, 273 (2011) 179-183.

[21] J.P.C. Ibrahim A. R. Al-Tisan, Abdulrehman Abanmy, a.A.M. Hassan, Optimization of seawater reverse osmosis pretreatment: Part III A microbiological approach, in, Research and Development Center, Saline Water Conversion Corporation, Al-Jubai, Kingdom of Saudi Arabia, 1995. 
[22] Y.-N. Kwon, J.O. Leckie, Hypochlorite degradation of crosslinked polyamide membranes: I. Changes in chemical/morphological properties, Journal of Membrane Science, 283 (2006) 21-26.

[23] S. Avlonitis, W.T. Hanbury, T. Hodgkiess, Chlorine degradation of aromatic polyamides, Desalination, 85 (1992) 321-334.

[24] V.T. Do, C.Y. Tang, M. Reinhard, J.O. Leckie, Degradation of Polyamide Nanofiltration and Reverse Osmosis Membranes by Hypochlorite, Environmental Science \& Technology, 46 (2012) 852859.

[25] V.T. Do, C.Y. Tang, M. Reinhard, J.O. Leckie, Effects of hypochlorous acid exposure on the rejection of salt, polyethylene glycols, boron and $\operatorname{arsenic}(\mathrm{V})$ by nanofiltration and reverse osmosis membranes, Water Research.

[26] N.P. Soice, A.C. Maladono, D.Y. Takigawa, A.D. Norman, W.B. Krantz, A.R. Greenberg, Oxidative degradation of polyamide reverse osmosis membranes: Studies of molecular model compounds and selected membranes, Journal of Applied Polymer Science, 90 (2003) 1173-1184.

[27] E. Lyster, Y. Cohen, Numerical study of concentration polarization in a rectangular reverse osmosis membrane channel: Permeate flux variation and hydrodynamic end effects, Journal of membrane science, 303 (2007) 140-153.

[28] K.J. Varin, N.H. Lin, Y. Cohen, Biofouling and cleaning effectiveness of surface nanostructured reverse osmosis membranes, Journal of membrane science, 446 (2013) 472-481.

[29] S.E. Duirk, D. Cherney, C. Tarr, T.W. Collette, Determining Active Oxidant Species Reacting with Organophosphate Pesticides in Chlorinated Drinking Water, in, U.S. Environmental Protection Agency, Washington DC, 2006.

[30] T. Oomori, T. Oka, T. Inuta, Y. Arata, The efficiency of disinfection of acidic electrolyzed water in the presence of organic materials, Analytical Sciences, 16 (2000) 365-370.

[31] C.J. Van Oss, Interfacial forces in aqueous media, CRC press, 2006.

[32] K.J. Moses, Y. Cohen, Wettability of terminally anchored polymer brush layers on a polyamide surface, Journal of Colloid and Interface Science, (2014).

[33] J.F. Watts, J. Wolstenholme, An introduction to surface analysis by XPS and AES, An Introduction to Surface Analysis by XPS and AES, by John F. Watts, John Wolstenholme, pp. 224. ISBN 0-47084713-1. Wiley-VCH, May 2003., 1 (2003).

[34] M. Mulder, Basic principles of membrane technology, Springer Science \& Business Media, 1996.

[35] I. Sutzkover, D. Hasson, R. Semiat, Simple technique for measuring the concentration polarization level in a reverse osmosis system, Desalination, 131 (2000) 117-127.

[36] A. Tang, O.C. Sandall, Diffusion coefficient of chlorine in water at 25-60. degree. C, Journal of chemical and engineering data, 30 (1985) 189-191.

[37] W. Hayduk, H. Laudie, Prediction of diffusion coefficients for nonelectrolytes in dilute aqueous solutions, AIChE Journal, 20 (1974) 611-615.

[38] HyperChem (TM), in, Hypercub, Inc., Gainesville, Florida.

[39] A. Kargol, Modified Kedem-Katchalsky equations and their applications, Journal of membrane science, 174 (2000) 43-53.

[40] W. Deen, Hindered transport of large molecules in liquid-filled pores, AIChE Journal, 33 (1987) 1409-1425.

[41] L.D. Nghiem, A.I. Schäfer, M. Elimelech, Removal of natural hormones by nanofiltration membranes: measurement, modeling, and mechanisms, Environmental science \& technology, 38 (2004) 1888-1896.

[42] P.M. Bungay, H. Brenner, The motion of a closely-fitting sphere in a fluid-filled tube, International Journal of Multiphase Flow, 1 (1973) 25-56.

[43] R.N. Wenzel, Resistance of solid surfaces to wetting by water, Industrial \& Engineering Chemistry, 28 (1936) 988-994. 